\title{
REGIONAL CHARACTERISTICS OF BUILDING SUPPLY IN A NEWLY DEVELOPED CITY IN JAPAN
}

\author{
Jun Tsutsumi \\ Geography Division, Faculty of Law and Letters, Ehime University \\ 3, Bunkyo-cho, Matsuyama, Ehime, JapanZip Code790-8577 \\ e-mail: jtsu@LL.ehime-u.ac.jp
}

\begin{abstract}
In this study the author undertook a micro-level analysis of the relationship between landownership change and the growth process of Sapporo city. The most important questions addressed by this paper are: Why the process occurred?; When did it occur?; Where did it take place?; Who was responsible?; and, How was it conducted? The author analyzed the long-term process of building supply and revealed how many renovation cases were identified that were brought about by newly advanced land purchasers, and how many cases were brought about by original land-owners without land-ownership change.
\end{abstract}

Key words: Japan, developed cities, land ownership change

\section{INTRODUCTION}

There is a body of literature concerning building location from the viewpoint of land price or category of land use (e.g., urban functions of office, shop and service activities). It is stated that an investigation of basic phenomena in the urban land market facilitates an understanding of impending land-use change or reorganization of urban structure. In addition, the life of high-rise office buildings is usually over 50 years; it's much longer than lowerrise ones. Hence, close observation of landownership is considered equally important. As Bryant et al. (1982) pointed out; changes in landownership were usually thought to precede land-use change. The investigation of landownership would be not only a good predictor of future land use, but also useful for analyzing urban growth (Tsutsumi, 1999; 2002; 2003).

To investigate the process of land-ownership change, the data housed in the Bureau of Legal Affairs in Sapporo were used. By using the data, it was possible to compile an array of information about land-ownership including the name and address of landowner, the lot size, the history of transactions (including the information of inheritance), and so forth. That is, the author could cover all the information about landowners in all the renovation cases. The land-use survey was conducted in August, 2001 and in June, 2002. Aerial pho- 
tographs, topographic maps and residential atlases were used to interpret former land-use. The author also used the detailed data of each building in the CBD (Microsoft Excelreadable format) provided by the urban planning division of Sapporo City Office. The author translated the data into the GIS attribute data. Spatial data framework, distributed in a CD-ROM media by the Ministry of Land, Infrastructure and Transport of Japan, were also used for the acquisition general vector data. Finally, a GIS package was used to assist in representing, processing, and visualizing (mapping) the data.

\section{OUTLINE OF SAPPORO CITY}

Sapporo city has a population of about 1.8 million in the 2000 census, which means the city is the $5^{\text {th }}$ biggest city in Japan. However the city has very short history of about 140 years compared to other major cities in Japan (Figure 1).

Figure 1: Study area of Sapporo city

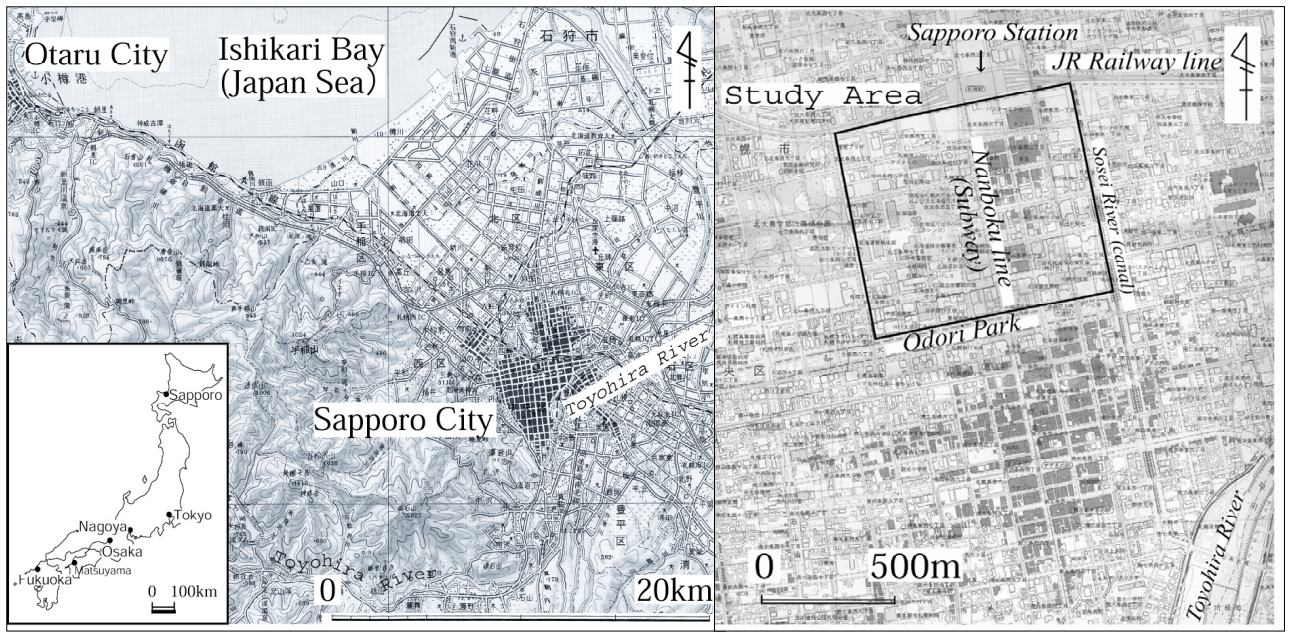

The new government, headed by the Meiji Emperor after the so-called Meiji Restoration in 1868 , was eager to establish a strong nation, both militarily stable and economically sound. The government was extremely interested in developing the frontier land of Hokkaido. For this purpose, it established the Kaitakushi (Development Commission) in 1869, a national government ministry devoted to planning and developing. Initially, a port was opened in Otaru, which is $34 \mathrm{~km}$ to the west of Sapporo. Consequently, Otaru played a very important role as a 'gateway' for development. Undoubtedly, Otaru was a naturally good port. However, the port was located beside mountains that permitted little room for city development.

Takeshiro Matsuura, as a Kaitakushi commissioner, strongly recommended that the capital of Hokkaido be established on the lshikari Plain (Figure 2). As a result, Yoshitake Shima was sent to Hokkaido as the commissioner responsible for founding a suitable place 
for a capital city. He planned a green belt dividing the city into north and south. This belt became the present Odori Park. It was decided that government buildings would be centred around the Kaitakushi office in the north, while to the south, amusement and commercial quarters would be located. The canal, which was built by Kametaro Otomo in 1866 to serve as the main route for irrigation and transportation, divided the city into east and west. The city began to develop around the park in a grid pattern. In addition, Japan's third operational railroad was established in 1880 between Sapporo and Otaru, which facilitated the growth of Sapporo. Due to the railroad, the station street which ran from north to south became much more significant to the city.

Figure 2: Locational features of Sapporo

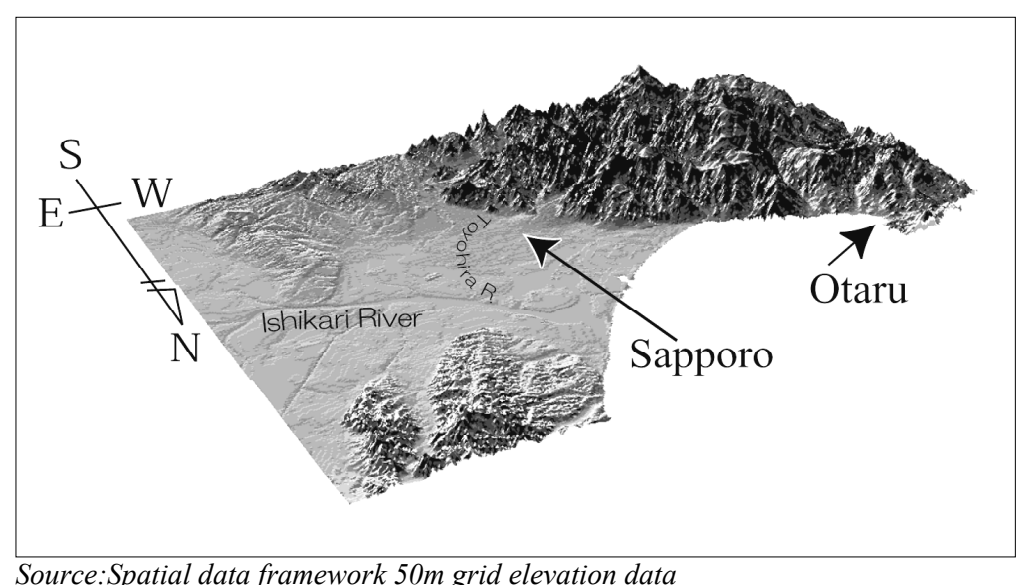

The present development greatly depended upon this original urban plan. The population of Sapporo city in 1945 was only about 200,000, which was less than other major cities in Hokkaido. The rapid rise of population started after the Hokkaido Comprehensive Development Plan, approved in 1950. This plan greatly encouraged leading business and manufacturers in Honshu (main island of Japan) to open branch offices in Sapporo. This industrial expansion brought with it a huge increase in population. With a population of over one million, as indicated by the 1970 census, Sapporo was designated as an ordinance-designated (autonomous) city on April 1st 1972. Also in 1972, Sapporo hosted the 11th Winter Olympic Games, which helped speed up improvements to urban infrastructure, including a subway system (www.global.city.sapporo.jp/knowmore/history/history.html).

Teraya (1993) analyzed the accumulation process of urban office functions using the number of branch offices of large companies based in big cities and indicated that about $60 \%$ of Japanese major companies didn't have branch offices in Sapporo. He also pointed out that the companies whose headquarters were in Tokyo established most of the branch offices in Hokkaido as 'Sapporo branch offices'. Sapporo chamber of commerce and industry (1988) reported that the numbers of establishments and employees of 'Sapporo branch offices' reached more than $40 \%$, which played important roles in the economy of the city. 


\section{CHARACTERISTICS OF BUILDING SUPPLY IN SAPPORO CITY}

Office buildings have been located mostly in the north of Odori Park in Sapporo. Therefore the author delimited the study area of building supply into the north of the park. As for the building supply in Sapporo city, two peaks were identified (Figure 3). The first period was in the years around 1972, which was the year of the Winter Olympics in Sapporo. The second peak was during the year after 1985. Several high-rise buildings were built in the CBD, but their locations tended to be away from the subway line for two reasons: higher land price; and no available space for new buildings along the subway line where already occupied by 1972 .

Figure 3: Number of construction of new buildings in the CBD of Sapporo

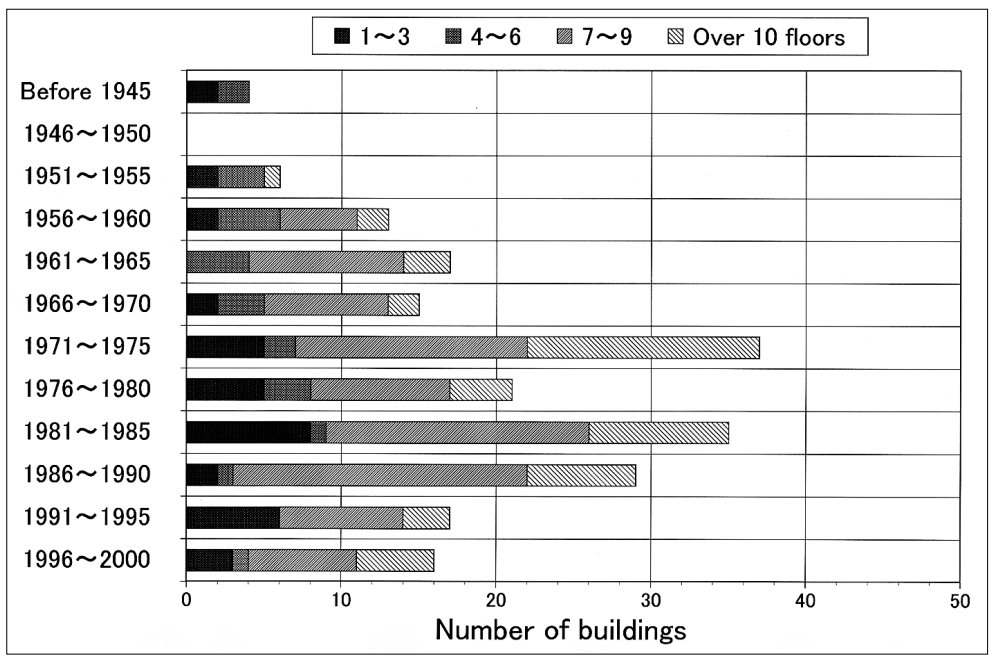

Source:Data from the Urban planning division of Sapporo city office

Figure 4(a) shows the floors of each building in the CBD of Sapporo. Higher buildings, for example more than 16 storied, tended to be located at the periphery of the study area. This meant their locations were away from the subway line, which was one of major growth axes of the city. On the other hand, along the subway line, relatively lower buildings, for example less than 10 storied, stood in a row.

Built year of each building in the CBD of Sapporo is shown in the Figure 4(b). Along the subway line, many old and large-lot buildings were found. Japanese major financial groups were the main providers of these buildings by 1972. This was because the transportation bureau of the city built a subway by 1972, which created a high demand for urban land along the subway line. Besides these old buildings, new buildings were provided during 1985-1995. Finally, the distribution of newest buildings tended to be in the periphery of the study area. With compared to the Figure 4(a), one important feature was identified. That was, newly built buildings include many high-rise ones and tended to be away from the subway line. 
Figure 4: Floors and built year of each buildings, and distributions of land price and buildings built after 1985 in the CBD of Sapporo

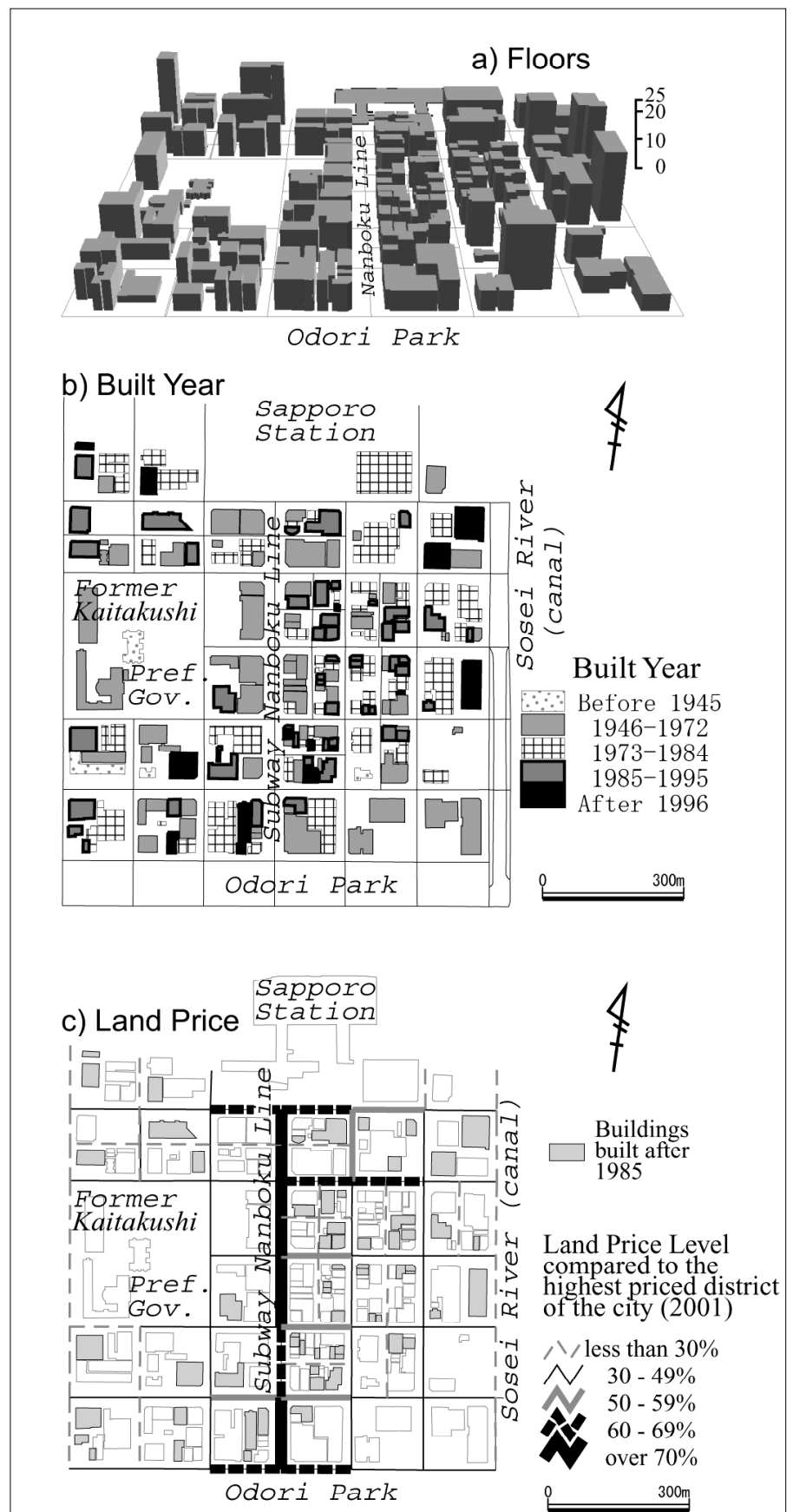

Source:Data from the Urban planning division of Sapporo city office and from the Sapporo Taxation Bureau 
This interesting fact became more evident in consideration of the relationship between the distributions of brand-new buildings and land price. The higher priced districts were distributed along the subway line, because these districts had good accessibility (Figure 4(c)). In general, the longer distance from the subway line, the cheaper the land price becomes. Figure 4(c) also shows the distribution of relatively new buildings built after 1985. Low-rise buildings constructed before 1972 mostly occupied land near the subway line. The lack of available land near the subway line, and the relative young age of existing buildings (around 30 years of a 50 year lifetime) has meant that the locations of the several high-rise buildings (over 16 stories) in the CBD tended to be away from the subway line. In general, land price of periphery area was less than half of the subway line where its land was highly priced. It's a significant characteristic of Sapporo compared to other big cities where we can find high-rise buildings in the highest priced district along the main streets of the cities. Whereas easy availability for providers of new buildings to find some suitable areas at a reasonable price was important in Sapporo, a characteristic pattern of building supply was identified.

\section{DISCUSSION FOR THE PROCESS OF BUILDING SUPPLY IN SAPPORO}

In this chapter, the author divided the total 63 cases into four groups (Type A - D) to find typical patterns for building supply by using detailed land-ownership data (Figure 5). These four groups were divided depending on the following indices: Did the land-owner change or not? If there were some changes in land-ownership, were they complete alterations, or partial changes? Finally, the characteristics of each four types were as follows: 'Type A' was mainly brought about by companies from Tokyo and Osaka who actively purchased some lots so that they could build their own buildings. In 'Type A', land-ownership was completely changed after land transaction. 'Type B' included some cases of partial landownership change where major financial companies in Japan became co-owners of brandnew high-rise buildings with original small shopkeepers. 'Type C' was characterized with reorganization programs conducted by the local government. 'Type D' was brought about by the same land-owners who continued to keep their land and have renovated the original old buildings (mostly low-rise single use) to larger ones by themselves.

'Type A' included 28 cases out of a total of 63. Distribution of this type tended to be an eastern part of the subway line where each lot was relatively smaller. 'Type B' concerned five complicated cases. Some individual shopkeepers who originally opened their shops (e.g., camera shop or small inn) in the CBD decided to join the large project financed by groups in Tokyo that already purchased larger adjacent lots. As a result, they became coholders of land on which new buildings stood. 'Type C' included only two cases. These two cases were not based on the decisions of landowners, but some reorganization programs conducted by the local government. It's true there appeared new larger buildings, but they could be considered as exceptional cases. Finally, on the other hand, distribution of 'Type D' was quite different compared to that of 'Type A'. The lot size of 'Type D' was 
relatively larger. 'Type D' also included 28 cases. The locations of newly built buildings brought about by this type of change were scattered among the CBD. The cases of building supply, which was brought about by major financial companies like cases of 'Type A', were quite popular in the CBD of major cities in Japan. However, the rate of renovation cases, which was brought about by the original owner, was also very high in Sapporo.

Figure 5: Spatial patterns of building supply in the CBD of Sapporo

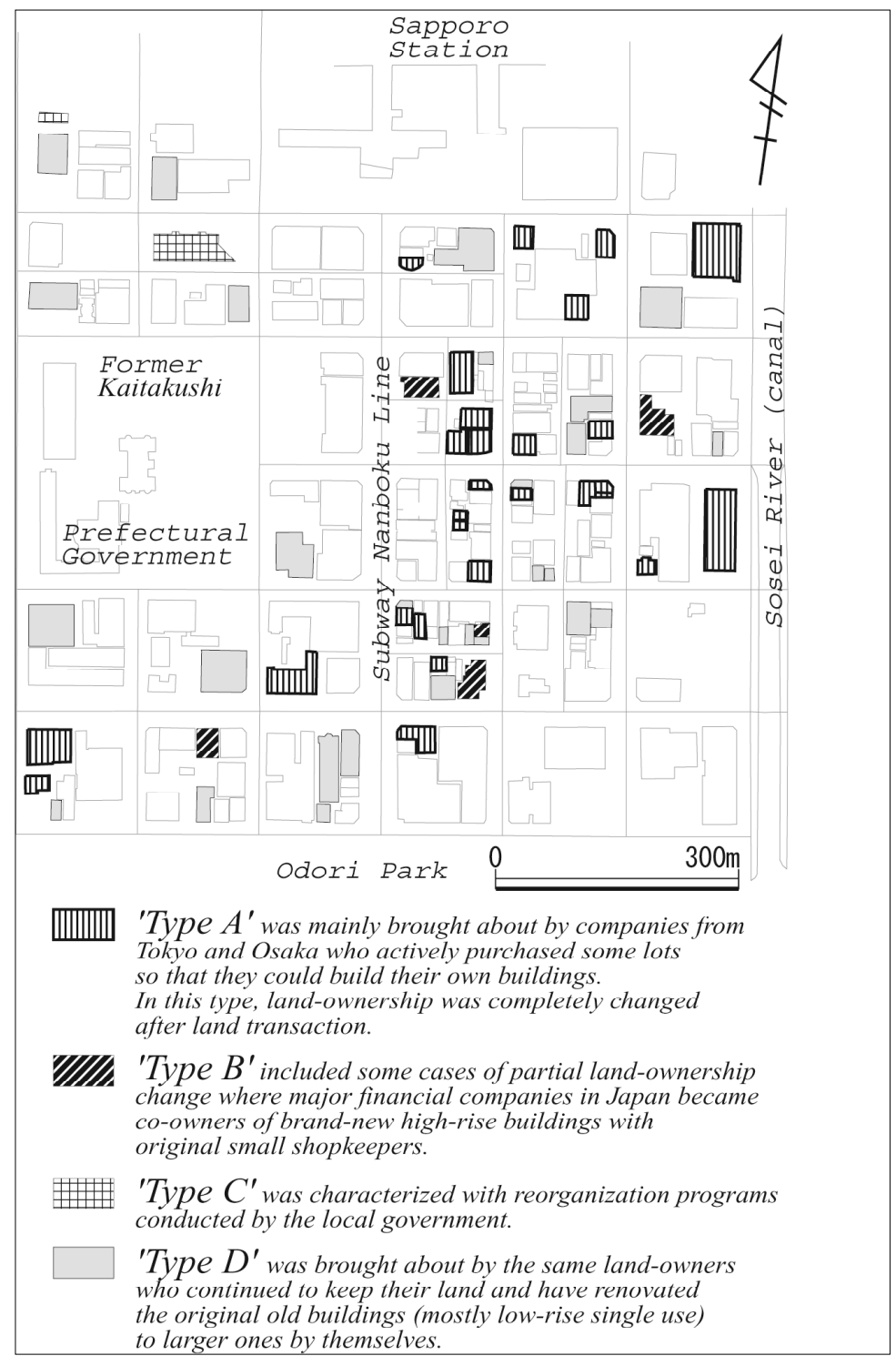

Source:Data from the Bureau of Legal Affairs in Sapporo 
From the viewpoint of land price, it is considered that the location of high-rise buildings tends to be limited to the highest priced districts. The reason for this is quite simple: the greater number of tenants and thus the higher buildings become, the easier the owners of buildings can pay the total cost. Matsuoka (1996) pointed out that high-rise buildings were found along the highest priced districts in Sendai city, the major city of northern part of Japan and with a population of 1 million. Yamashita (1999) also reported the same kind of tendency for the location pattern of high-rise buildings undertaking a case study of Tokyo. In addition, Tsubomoto (1994) identified the same kind of tendency with Sendai and Tokyo in Hiroshima city, while he also found some noteworthy tendencies that some brand-new buildings stood near the sub-centres of the city, for example the station street, where the land price were relatively cheaper than highest priced districts.

As the Figure 4(c) and Figure 6 shows, an unnatural relationship between the distribution of land price and the location of brand-new building was identified. The year of 1972 could be considered as a turning point for the city. Until then, a natural pattern of the location of high-rise building was identified: such buildings were located along the higher priced districts. A great number of brand-new buildings supplied in the city after 1972. Especially, as mentioned above, 'Type A' (newly purchased cases) and 'Type D' (renovated by the original owners) played pivotal roles for the growth of the city. Finally, an unnatural skyline of the urban landscape appeared in the city: high-rise buildings are located at the periphery; conversely, the main street along the subway line of higher priced districts is occupied by relatively lower buildings.

Figure 6: Schematic model of the process of building supply in Sapporo

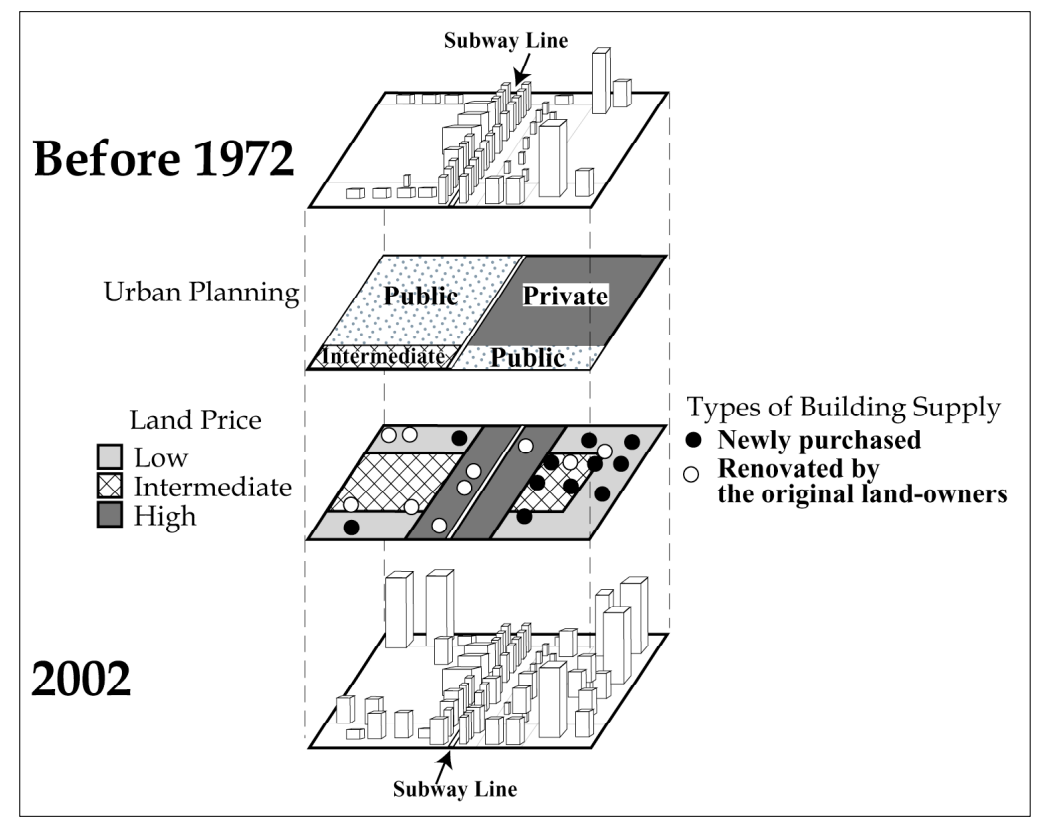


Given these general observations, Sapporo's case is identified as characteristic both in the process of building supply and in the distribution of high-rise buildings.

\section{SUMMARIES}

In this study the author undertook a micro-level analysis of the relationship between landownership change and the growth process of Sapporo city. The author analyzed how many renovation cases were identified that brought about by newly advanced land purchasers, while other renovation cases were brought about by original land-owners without landownership change. The result was summarized as follows:

As for the building supply in Sapporo city, two peaks were identified. The first period was in the years around 1972, which was the year of the Winter Olympics, held in Sapporo city. The second peak was during the year after 1985. Several high-rise buildings (over 16 stories) were built in the CBD, but their locations tended to be away from the subway line.

As for the process of land-ownership change, four major patterns were identified. Among them, following two types were identified as important: 'Type A' (newly purchased cases) and 'Type D' (renovated by the original owners). 'Type A' included 28 cases out of a total of 63 and was mainly brought about by companies from Tokyo and Osaka who actively purchased some lots so that they could build their own buildings. On the other hand, distribution of 'Type D' was quite different compared to that of 'Type A'. The lot size of 'Type D' was relatively larger. 'Type D' also included 28 cases and was brought about by the same land-owners who continued to keep their land and have renovated the original old buildings (mostly low-rise single use) to larger ones by themselves.

\section{Acknowledgements}

The author is grateful to Dr. Steven Phillips at the National Institute of Advanced Industrial Science and Technology (Japan) for his useful comments during the preparation of the English manuscript. In addition, appreciation is given to the officers in Sapporo City Hall and the Bureau of Legal Affairs in Sapporo who helped me in many ways by providing precious data and useful information.

\section{References}

Bryant, C.R., Russwurm, A.G., McLellan, A.G,. 1982: The city's countryside, land and its management in the rural-urban fringe. London: Longmans.

Matsuoka, K., 1996: The location and trend of high-rise buildings in Sendai. Quarterly Journal of Geography, 48, 293-302. (in Japanese only)

Sapporo chamber of commerce and industry, 1988. Actual situation of branch offices in Sapporo under a soft society. Sapporo chamber of commerce and industry, Sapporo, 120p. (in Japanese only) 
Teraya, R., 1993: Urban hierarchy in Hokkaido viewing from the processes of branch office placement of corporations. Chiri Kagaku, 48, 175-183. (in Japanese with eng. abstract)

Tsubomoto, H., 1994: Activities of private developers and office location in the central region of Hiroshima city. The Human Geography, 46, 418-434. (in Japanese with English Abstract)

Tsutsumi, J., 1999: Land Conversion due to Decision Agents in an Urban Land Market A Case Study of Maebashi City, Japan. Geographical Review of Japan Ser.B, 72, 23-47.

Tsutsumi, J., 2002: Land-use decisions and following land conversion process in a medium-sized city in Japan, in Kim, I., Nam, Y. and Choi, J., eds.: Diversity of Urban Development and Urban Life, Seoul National University Press, 164-179.

Tsutsumi, J., 2003a: The land conversion process and landowners' land-use decisions in the rural-urban fringe of Maebashi city. Geographical Review of Japan Ser.B 76 101-118

Tsutsumi, J., 2003b: Regional characteristics of building supply in the CBD of Sapporo city focusing on the analysis of land-ownership change. Journal of Geography (Japan) 112 Now Printing (in Japanese with English Abstract)

Yamashita, M., 1999: Tokyo toshinbu no kuukan riyou (Utilization of urban space in the CBD of Tokyo). Kokon Shoin, Tokyo, 174p. (in Japanese only) 